\title{
Photometrische Bestimmung von Bor im Grund- und Oberflächenwasser
}

Ulrike de la Chevallerie-Haaf, Axel Meyer und Günter Henze

Abteilung für Anorganische und Analytische Chemie der Universität Trier, Postfach 3825, D-5500 Trier, Bundesrepublik Deutschland

Photometric determination of boron

in ground- and surface water

Fresenius Z Anal Chem (1986) 323:266-270

Seite 267, linke Spalte, 5. Absatz, 3. Zeile:

Die Dimension des molaren Extinktionskoeffizienten muß richtig heißen: $\varepsilon=1,8 \cdot 10^{5} \cdot 1 \cdot \mathrm{mol}^{-1} \cdot \mathrm{cm}^{-1}$. 